\title{
El viaje renacentista y la visión estética del otro: \\ Una aproximación a la belleza y fealdad de la otredad en El primer viaje alrededor del mundo de Antonio Pigafetta (s. XVI).
}

The renaissance travel and the aesthetic vision of the other: an approach to the beauty and ugliness of otherness in Report on the First Voyage around the World by Antonio Pigafetta (s. XVI)

Pablo Castro Hernández ${ }^{1}$

\section{RESUMEN}

En este artículo analizamos la visión estética de la otredad en los viajes de Antonio Pigafetta (s. XVI). En primer lugar, revisamos la noción de la estética en el humanismo renacentista, examinando casos de intelectuales y artistas como parte de su contexto cultural. Posteriormente, estudiamos la percepción de la belleza y fealdad en el libro de viajes de Pigafetta, analizando su sensibilidad y visión estética sobre las otras culturas.

Palabras clave: Viaje - Estética - Belleza - Otredad - Pigafetta - Renacimiento

\section{ABSTRACT}

In this study, we analyze the aesthetic vision of the otherness in the voyages of Antonio Pigafetta (s. XVI). First, we review the notion of the aesthetic in the Renaissance humanism, examining cases of intellectuals and artists as part of their cultural context. Subsequently, we study the perception of the beauty and ugliness in the travel book of Pigafetta, analyzing his sensibility and aesthetic vision about other cultures.

Keywords: Travel - Aesthetic - Beauty - Otherness - Pigafetta - Renaissance

Recibido: enero 2018

Aceptado: junio 2018

${ }^{1}$ Licenciado en Historia de la Pontificia Universidad Católica de Chile y Magíster en Historia de la Pontificia Universidad Católica de Valparaíso. Profesor de Historia en la Universidad Alberto Hurtado, Universidad Academia de Humanismo Cristiano y Universidad Andrés Bello. Contacto: pfcastro@uc.cl 


\section{Una introducción a la percepción estética en los viajes renacentistas}

Los viajes significan expansión, apertura y encuentro. A través de éstos, los viajeros dialogan con otras culturas, establecen intercambios materiales e inmateriales y construyen representaciones e imágenes de la otredad. En esta línea es posible apreciar de qué manera los viajeros reflejan una visión estética y moral del otro, donde se establecen percepciones de belleza, agrado y hermosura, o bien fealdad, disgusto y desprecio tanto de lugares, culturas, animales u objetos.

Por visión estética entendemos el conjunto de elementos que se relacionan con la belleza y el sujeto que goza de la misma ${ }^{2}$. Jacob Burkchardt en su libro La cultura del Renacimiento en Italia, menciona cómo la belleza se vincula al espíritu de quien observa el objeto, generando una gran afición por su forma perfecta. La sociedad renacentista se deslumbra por árboles magníficos, personas hermosas y dignas, y animales bellos favorecidos por la naturaleza ${ }^{3}$. Según Umberto Eco, existe una proyección de la representación "clásica» de la belleza en el mundo moderno, donde lo bello, kalón, "es lo que gusta, lo que suscita admiración y atrae la mirada" 4 . Incluso, Arnold Hauser expresa que "por «bello» se entiende la concordancia lógica entre las partes singulares de un todo, la armonía de las relaciones expresadas en el número, el ritmo matemático de la composición, la desaparición de las contradicciones entre las relaciones de las figuras y el espacio" ${ }^{5}$. Sin ir más lejos, la belleza consiste en la proporción de las partes, una conveniencia y armonía de las $\cos ^{6}{ }^{6}$. En esta línea, podemos notar cómo los viajeros europeos que recorren otros lugares establecen sus apreciaciones estéticas de espacios, pueblos, animales u objetos. En cierta medida, tal como expresa Olaya Sanfuentes, hay un proceso de

\footnotetext{
2 Trías, Manuel. 1949. "El objeto de la estética", Actas del Primer Congreso Nacional de Filosofía, Mendoza, p.1553 y ss. Cabe mencionar que la estética significa "teoría de la sensación", lo cual se contrapone a la lógica: su objeto es el placer de lo bello [Schleiermacher, Friedrich. 2004. Estética, Madrid, Verbum, p.25]. Según Mauricio Beuchot, la estética es una teoría de la sensibilidad, la que se centra en una sensibilidad artística o gusto por la belleza. Así, "la experiencia estética se ve posibilitada por la inserción de ese trascendental de belleza, que se capta a partir del ser, que se obtiene mediante la experiencia misma del ser, experiencia profunda de éste, lo cual nos capacita para una experiencia profunda de la belleza" [Beuchot, Mauricio. 2012. Belleza y analogía. Una introducción a la estética, México D.F., San Pablo, p.12]. Incluso, Theodor Adorno señala que si bien la estética se vincula a una percepción de lo bello, esta a su vez requiere de la noción de lo feo. Hay una dialéctica que constituye este concepto, en la medida que la belleza no puede retener la identidad consigo mismo, sino que tiene que encarnarse en otras figuras que constituyen su opuesto [Adorno, Theodor. 1971. Teoría estética, Madrid, Taurus, pp.73 y ss.]. Desde nuestra mirada y como lineamiento a seguir en el estudio, consideramos que la visión estética constituye una relación con las percepciones de belleza y fealdad en un determinado momento histórico y cultural, de la cual es posible percibir una experiencia sensible y una representación de un objeto mediante juicios y categorías que definan una realidad. Para una mayor revisión sobre el concepto de estética, véase: Yarza, Joaquín. 2004. Introducción a la estética, Pamplona, EUNSA y Givone, Sergio. 1999. Historia de la estética, Madrid, Tecnos.

${ }^{3}$ Burckhardt, Jacob. 1952. La cultura del Renacimiento en Italia, Buenos Aires, Losada, p.113.

${ }^{4}$ Eco, Umberto. 2010. Historia de la belleza, Barcelona, Lumen, pp.39-41.

${ }^{5}$ Hauser, Arnold. 1969. Historia social de la literatura y el arte, Madrid, Guadarrama, p.359.

${ }^{6}$ Cfr. Eco, Umberto. 2010. Historia de la belleza, pp.214-216.
} 
europeizar lo diferente, donde los indígenas son atrapados por una belleza clásica propia de la tradición y cultura europea ${ }^{7}$.

Bajo este contexto, podemos situar al cronista y navegante italiano Antonio Pigafetta, en su obra El primer viaje alrededor del mundo, escrito hacia 1525, quien se refiere a la expedición realizada por Fernando de Magallanes y Juan Sebastián Elcano que parte desde Europa y se dirige hacia el Nuevo Mundo, Asia y África, en la cual logran dar la primera vuelta al mundo entre los años 1519 y 1522. Cabe mencionar que este navegante realiza una anotación de los diversos pueblos que observa en su trayecto, dando cuenta de sus costumbres, modos de vida, prácticas políticas, religiosas y sociales, entre otras.

Ahora bien, nuestro problema de investigación se centra en analizar la visión estética de la otredad que construye Antonio Pigafetta en su relato de viajes y bajo qué categorías aplica los cánones de belleza y fealdad en las otras culturas, y si éstas se encuentran en relación a la percepción estética que poseen sus coetáneos sobre los otros. En otras palabras, se intenta develar si el navegante italiano utiliza o no juicios de valor o estéticos sobre las cosas que observa en las tierras que recorre y qué elementos considera como parte del canon de su concepción estético-moral.

En primer lugar, analizamos la visión de la belleza y fealdad de su época, considerando los planteamientos de humanistas, intelectuales y artistas del Renacimiento. Posteriormente, revisamos el caso de Pigafetta, dando cuenta de las influencias recibidas por la tradición humanística y los conceptos aplicados por el viajero en la visión estética de la otredad en sus viajes alrededor del globo.

Consideramos que el viajero italiano sí utiliza una visión estética de elementos 'bellos' y 'feos' que aplica en las cosas que observa en las tierras que recorre. Particularmente, en el caso de los cuerpos físicos de la otredad, aprecia nociones de 'buena disposición', 'belleza', 'fealdad' o 'ridiculez' ${ }^{8}$, basado en aspectos de armonía y proporción de las cosas, propias de su contexto cultural. En el caso del cuerpo de la otredad, se resaltan elementos idealizados de la desnudez, lozanía y piel clara, que Pigafetta constantemente relaciona que se asemejan a los del mundo europeo. En tanto que la fealdad es asimilada en torno a la desproporción, la piel oscura o lo grotesco de algunos cuerpos. En cierta medida, notamos cómo el viajero posee un espíritu humanista, estableciendo juicios estéticos sobre el otro a partir del legado de intelectuales y artistas de su época, que aplican dicho léxico para referirse a las cosas bellas o feas, lo que finalmente responde a un juicio de sensibilidad asentado en la particularidad y subjetividad del ojo del sujeto que contempla su objeto. En suma, con la visión estética de Pigafetta apreciamos juicios basados en el concepto histórico-cultural de su tiempo plasmado en los nativos y

\footnotetext{
${ }^{7}$ Cfr. Sanfuentes, Olaya. 2009. Develando el Nuevo Mundo. Imágenes de un proceso, Santiago, Ediciones UC, p.194.

${ }^{8}$ En las ediciones de Pigafetta de la época se utiliza la terminología 'ben disposto', 'ben fatto di corpo' y 'molto belle' para referirse a lo bello, como también términos como 'brutte' y 'molto ridicula' para referirse a las nociones de fealdad.
} 
elementos naturales que observa en sus viajes. En este sentido, sus categorías toman como centro el modelo de belleza y fealdad renacentista, que tienen como base las medidas y proporciones de las cosas, lo que genera asombro y admiración en el viajero.

\section{Revisión de fuentes: los manuscritos y las ediciones impresas de Pigafetta}

Actualmente el primer escrito sobre la relación de viaje redactado por Antonio Pigafetta no se conserva, sin embargo, dicho texto sobrevive en cuatro manuscritos derivados de aquella relación redactados en la misma época. Según Theodore Cachey, el texto de Pigafetta se encuentra en los siguientes manuscritos: uno italiano ( $D=$ Milán, Bib. Ambrosiana, L.103 Sup.) y

tres franceses $(A=$ París, Bibliothèque Nationale, MS 5650); $(B=M S$. fr.24224); y $(C=$ Yale University, Beinecke Rare Book and Manuscript Library, Phillips MS 16405) ${ }^{9}$.

Tal como indica James Alexander Robertson, el más antiguo de estos manuscritos es el italiano, que fue encontrado por Carlo Amoretti, archivero de la biblioteca Ambrosiana, a fines del siglo XVIII. Este texto escrito en italiano, se ha datado alrededor de $1524-1525^{10}$. Cabe señalar que este manuscrito es una copia derivada de la relación original, el cual está dedicado a Philippe de Villiers de L'Isle-Adam, el gran maestre de Rodas ${ }^{11}$. De esta obra disponible en la biblioteca Ambrosiana, Amoretti preparó dos ediciones; una italiana titulada Primo viaggio intorno al globo terracqueo ossia Ragguaglio della Navigazione alle Indie Orientali per via d'occidente fatta dal cavalieri Antonio Pigafetta patrizio vicentino Sulla Squadra del capit.

\footnotetext{
${ }^{9}$ Cachey Jr., Theodore. 2007. "Bio-bibliographical note". En Antonio Pigafetta, The first voyage around the world 1519-1522. An account of Magellan's expedition, Toronto, Buffalo, Londres, University of Toronto Press, p.xlvi.

10 Robertson, James Alexander. 1906. "Bibliography of Pigafetta manuscripts and printed books". En Antonio Pigafetta, Magellan's voyage around the world, vol. 2, Cleveland, The Arthur H. Clark Company, p.243. La datación del texto L 103 sup., texto revisado por Amoretti, puede consultarse en el catálogo de la Biblioteca Ambrosiana: http://ambrosiana.comperio.it/opac/detail/view/ambro:catalog:77338 (Noviembre, 2017).

${ }^{11}$ Cabe mencionar que Antonio Pigafetta al llegar de su viaje a Valladolid, España, le entregó una copia al emperador Carlos $\mathrm{V}$, conservando el viajero italiano las notas de su manuscrito original. A esta audiencia asistió también el secretario particular del monarca, Maximiliano de Transilvania, que la relató en una carta del 21 de octubre de 1522 al cardenal de Salzburgo. La copia que entregó Pigafetta al emperador fue utilizada por Pedro Mártir de Anglería para hacer una nueva redacción y enviársela al papa Adriano VI, la cual fue enviada de manera posterior, cuando el pontífice ya se encontraba muerto. Sin embargo, el documento realizado por Anglería desapareció durante el saqueo de Roma durante 1527. Por otra parte, la copia entregada al emperador también se encuentra perdida, quedando solo la carta redactada por Maximiliano de Transilvania [Pinkerton, John. 1819. "Pigafetta voyage round the world", A general collection of the best and most interesting voyages and travels in various parts of America, vol. I, Longman, Hurst, Rees and Orme and Brown, Londres, p.299 y Walls y Merino, Manuel. 1899. "Prólogo del traductor". En Antonio Pigafetta, Primer viaje alrededor del mundo, Madrid, pp.XXXV y ss.]. Posteriormente, Pigafetta hizo una copia del manuscrito original estando en Italia, para obedecer los ruegos del papa Clemente VII y el gran maestre de Rodas. Además, "como en este libro añade Pigafetta a su nombre el título de caballero, puede deducirse que lo escribió después del 3 de octubre del año 1524, día en que fue nombrado caballero". Así, esta obra la escribió algunos años después de la vuelta de su viaje, teniendo "las notas originales mientras la redactaba, porque dice repetidas veces oggi (hoy) copiando lo que había escrito el mismo día del suceso. Además, no le hubiera sido posible, siguiendo el orden del tiempo más que el de las cosas, conservar la memoria de una infinidad de objetos para él nuevos y de acontecimientos extraordinarios" [Ruiz M., Federico. 1922. "Prefacio del traductor francés". En Antonio Pigafetta, Primer viaje en torno del globo, Calpe, Madrid, pp.20 y ss.]
} 
Magaglianes, publicada en 1800, y una traducción en francés titulada Premier voyage autour du monde par le chevalier Francesco Antonio Pigafetta sur l'escadre de Magellan, en $1801^{12}$.

Respecto a los manuscritos franceses, dos se encuentran en la Biblioteca Nacional de París, con los siguientes títulos: Navigation et descouvrement de la Indie superieure faicte par moi Anthoyne Pigaphete Vincentin chevallier de Rhodes (A) y Navigation et discovrement de a Indie superieure faicte par moy Anthoine Pigaphete vincentin chevalier de Rhodes (B), datados durante el siglo XVI. El tercer escrito, datado durante ese mismo siglo, se halla en la colección privada de sir Thomas Phillips, el cual se titula Navigation et descovrement de a Indie superiore et isles de Malucque ou naissent les cloux de Girofle. Faicte par Anthoine Pigaphete patricie vincentin chevalier de Rhodes $(\mathrm{C})^{13}$.

En cuanto a las ediciones impresas, María Laura de Arriba indica que se publicó una traducción en francés por el librero Simone Colines en París, entre 1526 y $1536^{14}$. Tiene 104 capítulos y lo tituló Le voyage et navigation faict par les Espaignolzes isles de Mollucques, des isles quilz ont trouvé audict voyage, des roys d'icelles, de leur gouvernement et manière de vivre, avec plusieurs autres choses. Este escrito se trata de un resumen en francés del texto italiano que fue encargado por María Luisa de Saboya, que ya había recibido de manos de Pigafetta algunos regalos como recuerdo de su viaje ${ }^{15}$. Tal como indica Isabel de Riquer, de este libro en francés se imprime en 1536 una edición italiana dentro de un volumen con otros textos sobre el mismo viaje; la obra se titula II viaggo fatto dagli Spagnoli atorno al mondo y le precede una carta de Maximiliano de Transilvania (Bibl. Amer. Vetus, no192). La segunda edición es de 1550 y se encuentra en la colección de Gian Battista Ramusio, Navigazioni e viaggi, que es una obra que tuvo diversas ediciones, publicando testimonios de primera mano de varios exploradores tardo medievales y renacentistas ${ }^{16}$. Luego la obra sería traducida al inglés por Richard Eden en sus Decades en $1555^{17}$.

\footnotetext{
12 De Riquer, Isabel. 1999. “Introducción”. En Antonio Pigafetta, El primer viaje alrededor del mundo. Relato de la expedición de Magallanes y Elcano, Barcelona, Ediciones B, pp.63-64.

13 Robertson, James Alexander. 1906. "Bibliography of Pigafetta manuscripts and printed books", pp.248 y ss.; y Cachey Jr., Theodore. 2007. "Bio-bibliographical note", p.xlvii.

${ }^{14}$ De Arriba, María Laura. 2004. "Los sonidos de la enunciación en la primera vuelta al mundo", Revista de Crítica Literaria Latinoamericana, Año XXX, núm. 60, Lima-Hanover, p.57.

${ }^{15}$ De Riquer, Isabel. 1999. "Introducción", pp.62-63. Cabe señalar que después de haber escrito su libro para el Gran Maestre de Rodas, envió una copia a la reina Luisa de Saboya, regente del reino por su hijo Francisco I, a la cual se había presentado Pigafetta cuando regresó a Italia para ofrecerle algunos productos del otro hemisferio. La reina encargó la traducción del libro al francés a Fabre, quien hizo solamente un extracto [Ruiz M., Federico. 1922. "Prefacio del traductor francés", p.22].

${ }^{16}$ Ibíd.

${ }^{17}$ Robertson, James Alexander. 1906. "Bibliography of Pigafetta manuscripts and printed books", pp.288 y ss. Cabe señalar que durante los siglos XIX y XX se realizan diversas traducciones italianas, inglesas, alemanas y españolas. Para una revisión a las ediciones y traducciones, véase: Cachey Jr., Theodore. 2007. "Bio-bibliographical note", p.xlvi.; De Riquer, Isabel. 1999. "Introducción”, pp.62-67; Walls y Merino, Manuel. 1899. "Prólogo del traductor", pp.XXXV y
} 
Para el presente estudio hemos revisado las siguientes ediciones de Pigafetta: La edición italiana Primo viaggio intorno al globo terracqueo de Carlo Amoretti del códice de 1524-1525 (L 103 sup. de la Biblioteca Ambrosiana de Milán) ${ }^{18}$. La edición francesa Le voyage et navigation faict par les Espaignolzes isles de Mollucques del librero Simone Colines de París, 1526-1536 ${ }^{19}$. La versión italiana de II viaggo fatto da gli Spagniuoli a torno a'l mondo de $1536^{20}$. La edición italiana de Pigafetta incluida en la obra de Gian Battista Ramusio, Navigazioni e viaggi, de $1550^{21}$.

Asimismo, contamos con una edición reciente en español sobre la obra de Pigafetta, con la cual realizamos una revisión de los pasajes que abordan el plano estético y contrastamos con las versiones originales de la obra del viajero italiano ${ }^{22}$.

Finalmente, hemos considerado diversos escritos literarios y artísticos del Renacimiento, situados entre los siglos XV y XVI, con los cuales se examina la visión estética de los intelectuales y humanistas de esta época. Mediante esta selección de fuentes, se analiza el uso de conceptos estéticos abocados a la belleza y fealdad, y de qué manera son aplicados tanto en el ámbito literario, artístico y cultural ${ }^{23}$.

\section{Un estado del arte sobre la visión estética en los viajes de Pigafetta: algunas líneas y problemáticas de estudio}

La discusión historiográfica de este tema es escasa en el viajero italiano. Isabel de Riquer señala que Pigafetta no muestra excesivo asombro ante las novedades, no se horroriza ni rechaza las costumbres entonces consideradas insólitas de las culturas. Solo en algunos casos considera

ss.; Ruiz M., Federico. 1922. "Prefacio del traductor francés”, pp.20 y ss.; y De Arriba, María Laura. 2004. "Los sonidos de la enunciación en la primera vuelta al mundo", pp.57-58.

18 Antonio Pigafetta, Primo viaggo intorno al globo terracqueo, 1524-1525. Disponible en: http://bdhrd.bne.es/viewer.vm?id=0000060992\&page $=1$ (Noviembre, 2017).

${ }^{19}$ Antonio Pigafetta, Le voyage et navigation faict par les Espaignolzes isles de Mollucques, 1526-1536. Disponible en: https://archive.org/details/levoyageetnauiga00piga (Noviembre, 2017).

20 Antonio Pigafetta, II viaggo fatto da gli Spagniuoli a torno a'l mondo, 1536. Disponible en: http://www.europeana.eu/portal/record/2048604/data_item_onb_abo_2BZ156386803.html?start=8\&query=who \%3Aantonio+pigafetta\&startPage=1\&qt=false \&rows=24 (Noviembre, 2017).

21 Gian Battista Ramusio, Navigazioni e viaggi. Disponible en: http://www.europeana.eu/portal/ record/92004/BibliographicResource_2000059207873.html?start=19\&query=who\%3Aramusio\&startPage=1\&qf=TYP E\%3ATEXT\&qt=false\&rows=24 (Noviembre, 2017).

${ }^{22}$ Antonio Pigafetta, El primer viaje alrededor del mundo. Relato de la expedición de Magallanes y Elcano, ed. Isabel de Riquer, Barcelona, Ediciones B, 1999.

${ }^{23}$ Cabe mencionar que dentro de las fuentes que se utilizan para el estudio y que se complementan en el análisis de la obra de Pigafetta, se han considerado los siguientes documentos: Francesco Petrarca, De los Remedios contra Próspera y Adversa Fortuna (1360-1366); Giovanni Francesco Pico della Mirandola, Comentario a la obra Dell'amore celeste e divino: Canzone de Girolamo Bieniveni (c.1500); Pietro Bembo, Gli Asolani (1497-1502); Leon Battista Alberti, Tratado de Arquitectura (1449-1450); y Leonardo da Vinci, Tratado de la Pintura (1651). Se han escogido estos documentos de intelectuales y humanistas, principalmente por su mención acerca de los conceptos de belleza y fealdad aplicados al arte y la literatura del Renacimiento, reflejando percepciones y sensibilidades estéticas de su realidad cultural. 
que el cronista italiano usa hipérboles de admiración, tales como un «espectáculo bellísimo de ver», ya sean mujeres, animales, frutas o paisajes ${ }^{24}$. No obstante, la autora solo lo aborda como una exageración retórica, en la cual no analiza la naturaleza conceptual de la belleza, sino que solo la relaciona a un plano admirativo.

Josué Sánchez realiza un acercamiento al análisis de las primeras visiones estéticas de América, en la cual menciona que Pigafetta se refiere a gigantes de 'hermosa talla' y ciertas mujeres indoamericanas 'feas' ${ }^{\prime 25}$, aunque no profundiza la categoría conceptual utilizada por el viajero y el contexto del canon de belleza y fealdad de la época.

Por otro lado, Stefanie Massmann señala que Pigafetta se refiere al estrecho de Magallanes como el espacio 'más hermoso', esto dado por las ventajas geo-políticas y económicas, basado en las curiosidades y maravillas de las nuevas tierras que se exploran y que abre otros nodos comerciales $^{26}$. Incluso, Ilaria Luzzana Caraci menciona que Pigafetta observa y apunta usos y costumbres de indígenas, pero no expresa juicios sobre ellos $^{27}$. En cierta medida, siguiendo esta última mirada, el viajero intenta comprender y racionalizar al otro, generando descripciones exactas y minuciosas de las cosas nuevas, pero no realiza juicios de valor o estéticos sobre la otredad.

Considerando estos planteamientos, podemos notar de qué manera el problema de la visión estética en el relato de viajes de Pigafetta, deja ciertos vacíos conceptuales que aún faltan precisar. Consideramos que en el texto de Pigafetta sí encontramos una visión estética plasmada por el autor, en la cual expresa tanto un sentido de belleza y otro de fealdad en lugares, pueblos, animales y objetos materiales que observa en Asia, África y el Nuevo Mundo. Sin ir más lejos, el viajero para referirse a los cuerpos de los pueblos que observa utiliza conceptos como 'buena disposición', 'belleza' y 'bien hecho', además de criticar en algunos casos a algunos pueblos por su 'fealdad' y 'ridiculez'. En este sentido, no podemos considerar lo que autores como llaria Luzzana Caraci e Isabel de Riquer señalan sobre la relación de Pigafetta, en cuanto no emite juicios de valor o estéticos en su obra, o que son meras hipérboles de admiración. Si bien en algunos pasajes refleja una descripción minuciosa y racionalización de las culturas y elementos naturales que observa, omitiendo comentarios de juicio sobre el otro, no podemos generalizar su obra en esa línea, puesto que el cronista italiano se apoya en una tradición de la visión estética aplicada por sus contemporáneos humanistas y artistas, donde expresan miradas positivas y negativas de la realidad que observan, manifestando juicios estéticos de la otredad.

\footnotetext{
${ }^{24}$ De Riquer, Isabel. 1999. “Introducción”, pp.38-39.

25 Sánchez, Josué. 2011. "La primera visión europea estética de los indoamericanos en la invasión de América", Anuario Americanista Europeo, núm. 9, pp.95-96.

${ }^{26}$ Massmann, Stefanie. 2014. "Geografías del imperio: utopía y desencanto en las representaciones del Estrecho de Magallanes (1520 y 1620)", Hispanófila, 172, p.28.

${ }^{27}$ Luzzana C., Ilaria. 1992. Navegantes italianos, Madrid, Mapfre, p.292.
} 


\section{La visión estética del Renacimiento. Una aproximación a las nociones de 'belleza', 'buena disposición', 'fealdad' y 'ridiculez'}

La estética renacentista de los siglos XV y XVI se desarrolla principalmente a través de las ideas filosóficas, artísticas y humanísticas de la época. Tal como expresa Raymond Bayer, hay un gusto por el mundo sensible, donde el universo material inspira amor por sí mismo, ya no solo en un sentido simbólico, estableciendo un acercamiento al cuerpo y las figuras humanas ${ }^{28}$. En cierta medida, hay una proximidad a la naturaleza, en la cual la belleza ya no es solo lo inteligible o lo metafísico, sino que también se aprecia en torno a su propia realidad material ${ }^{29}$.

Durante el Renacimiento, es posible apreciar diversas perspectivas en torno a la visión de la belleza forjada por intelectuales y artistas que profundizan en ciertos lineamientos estéticos de la realidad. Hay un interés por la belleza sensible, donde el hombre deja de anular la sensualidad, sino que intenta glorificarla a través del arte, la poesía o las diversas manifestaciones de la creación humana que reflejen un goce estético del sujeto. Tal como expresa Wladyslaw Tatarkiewicz, basándose en la postura de Petrarca, la belleza es un punto intermedio entre lo 'perfecto' y lo más 'grato', que hace que una cosa sea superior. En cierta medida, "el juicio de que algo es grato o hermoso no es un juicio sobre el objeto, sino sobre la relación del hombre ante ese objeto", lo que se constituye como un juicio estético subjetivo ${ }^{30}$.

En otras palabras, la belleza va adoptando una postura más particular, centrada en el individuo, quien emite un juicio a partir de su propia sensibilidad. David Summers sostiene que se desarrolla un "punto de vista» que remite a la subjetividad e individualidad, donde la esfera

\footnotetext{
${ }^{28}$ Bayer, Raymond. 2002. Historia de la estética, México D.F., Fondo de Cultura Económica, p.101

${ }^{29}$ Cabe destacar que existe un mayor interés por la representación de la realidad material basada en su propia naturaleza, una naturaleza tal como se muestra a los ojos, la que produce un aumento en la sensación de realidad [Cfr. Gombrich, Ernst. 2007. La historia del arte, Londres, Phaidon Press, pp.233 y ss.]. Los artistas renacentistas si bien pueden evocar lo sobrenatural, milagroso o místico, esto queda reducido a lo "natural», entendido como un espacio calculado, como parte del nuevo saber pictórico [Tenenti, Alberto. 2000. La Edad Moderna, siglos XVI-XVIII, Barcelona, Crítica, pp.20 y ss.]. Junto con esto, notamos cómo el siglo XV es uno de los grandes siglos de la técnica, esto es, el desarrollo de nuevo instrumentos y su explotación tanto en el espacio y en el terreno de la representación. En esta línea, el artista renacentista tiende a representar la realidad material buscando lo bello y lo útil [Chastel, André. 1990. "El artista". En Eugenio Garin, El hombre del Renacimiento, Madrid, Alianza, pp.231-332] Hay que tener presente que los artistas de este tiempo reúnen diversos conocimientos, tanto en perspectiva, anatomía, expresividad emocional y monumentalidad, lo cual va forjando un nuevo estilo artístico que conduce a la imitación en la vida. Hay una búsqueda de efectos espaciales amplios y coherentes, un retratismo que resalta el trabajo de la inteligencia y una copia directa de la naturaleza. Se idealiza a la figura humana, perfectamente integrada, ya sea en un escenario arquitectónico o en un paisaje [Hale, J. R. 1993. La Europa del Renacimiento, 14801520, Madrid, Siglo XXI Editores, pp.314-315]. Sin ir más lejos, en el arte se busca "una mayor pureza de líneas, más austera y 'literal', no tanto 'alegórica' o simbólica, y esta limpieza o luminosidad es vista como apego a la razón" [Beuchot, Mauricio. 2012. Belleza y analogía, p.43]. Incluso, notamos como hay una mayor proximidad a la naturaleza, la cual se convierte "en el espectáculo máximo para el artífice y en el gran modelo creador a imitar"; es una imitación que busca encarnar ejemplares perfectos e ideales de la realidad [Plazaola, Juan. 2007. Introducción a la estética. Historia, teoría, textos, Universidad de Deusto, Bilbao, p.77].

${ }^{30}$ Tatarkiewicz, Wladyslaw. 1991. Historia de la Estética, La estética moderna, 1400-1700, III, Madrid, Akal, 1991, p.16.
} 
de lo real es apreciada bajo un ojo particular, específico, "una forma de alma humana, a la disposición de la materia que constituye el principio de diferenciación de un individuo frente a otro" $^{\prime 31}$. En esta línea, notamos cómo la percepción de la belleza o la fealdad adquiere tintes más personales, basados en la sensibilidad del sujeto que aprecia el objeto en sí.

En el comentario de Giovanni Francesco Pico della Mirandola a la obra Dell'amore celeste $e$ divino: Canzone de Girolamo Bieniveni, escrita alrededor de c.1500, nos menciona el concepto de belleza de su época:

"En la belleza de los cuerpos, que nos manifiesta a la luz del día, dos cosas se revelan a quien bien las considera. La primera es la disposición material del cuerpo, la cual consiste en la debida cantidad de sus partes, así como en la conveniente cualidad. La cantidad en el tamaño de los miembros, según la conveniente proporción respecto del conjunto y en el lugar y distancia respectiva entre unos y otros, consistiendo la cualidad en la figura y el color. En cuanto a la segunda es cierta cualidad que por su nombre adecuado se puede llamar gracia, cosa que se parece y resplandece en las cosas bellas" ${ }^{32}$.

Mediante este pasaje podemos vislumbrar cómo la belleza se define a partir de la dispozicione del corpo [disposición del cuerpo], basada en una debida cantidad de sus partes, lo que en términos de proporción resulta bello y agradable para las personas. Junto con esto, se expresa la gracia, que a su vez hace resplandecer las cosas en sí. Tal como manifiesta Wladyslaw Tatarkiewicz, "lo bello consiste en una esplendorosa y elegante disposición de diversas partes de las que nace y emana la belleza" ${ }^{33}$. En cierta medida, la noción de belleza contempla una conveniente proporción de los miembros corporales, que estén bien hechos y que deslumbren por su gracia y naturaleza.

Francesco Petrarca en los diálogos del Júbilo y la Razón en su obra De los Remedios contra Próspera y Adversa Fortuna, escrita entre 1360-1366, menciona la relación entre belleza corporal y la belleza del alma:

\footnotetext{
${ }^{31}$ Summers, David. 1993. El juicio de la sensibilidad. Renacimiento, naturalismo y emergencia de la Estética, Madrid, Tecnos, 1993, p.423.

32 G. Pico della Mirandola, "La disposición y la gracia", Comento a la Canzone di G. Benivieni (ed. 1731). En Tatarkiewicz, Wladyslaw, Op.cit., p.155. «E'adunque da considerare, che nella Belleza de' corpi, che a noi nella luce del di si manifesta, due cose appajono a chi bene le considera. La prima è la materiale dispozisione del corpo, la quale consiste nella debita quantità delle fue parti, en ella conveniente qualità. La quantità e, en nella grandezza de'membri, fe ella è secondo la proporzione del tutto conveniente, en el sito loro, e distanza dell' uno, e dell' altro. La qualità è nella figura, en el colore. La seconda è una certa qualità, che per più proprio nome, che di grazia non fi può chiamare, la quale appare, e risplende nelle cose belle» [Giovanni Francesco Pico della Mirandola; Girolamo Benivieni, Dell'amore celeste e divino: Canzone, Lucca, 1731, Cap. X, p.112. Disponible en: http://reader.digitalesammlungen.de/de/fs1/object/display/ bsb10754248_00132.html] (Noviembre, 2017).

${ }^{33}$ Tatarkiewicz, Wladyslaw. 1991. Historia de la Estética, p.91.
} 
"JÚBILO: La belleza del cuerpo es extraordinaria [...] es formidable [...] es la más exquisita [...] es admirable [...] es grande [...] es peculiar [...] es manifiesta [...] es eminente. RAZÓN: ¡Cuánto preferiría yo la belleza superior del espíritu! La suya es, en efecto, una hermosura del alma, mucho más agradable y fundada que la del cuerpo, y que se apoya ella misma también en sus leyes por el atractivo del orden y por la adecuada disposición de sus partes [...] JÚBILO: Deseo que la virtud del espíritu esté unida a la belleza del cuerpo" ${ }^{34}$.

En este pasaje podemos observar cómo Petrarca no solo aboga por la belleza corporal, basada en un cuerpo excelente, sino que también se debe cultivar una belleza del alma. Según Wladyslaw Tatarkiewicz, esta belleza corporal considera objetivos elogiosos -egregia, eximia, magna, elegante, asombrosa, esplendorosa, extraordinaria y excelente-, pero también afirma que la razón critica esta belleza corporal por ser poco duradera ${ }^{35}$. Cabe señalar que tanto la belleza corporal y espiritual poseen apta suarum partium dispositione, esto es, una disposición adecuada en todas sus partes. En cierta medida, se aprecia un sentido de proporción tanto en la forma y el espíritu, donde ambas deben establecer un orden que genere un sentido de superioridad basada en la belleza del alma.

Asimismo, Pietro Bembo en su obra Gli Asolani, escrito entre 1497-1502 y publicado en una edición de 1525, señala lo siguiente sobre la belleza:

“Ella (la belleza) no es sino una gracia que nace de la proporción y conveniencia, y aun de la armonía de las cosas, la cual, cuanto más perfecta resulta en sus frutos, más amable y hermosa se nos hace, siendo en el hombre accidente, no menor respecto al ánimo que al cuerpo. Por lo cual, así como es bello el cuerpo cuyos miembros mantienen entre sí su proporción, así es bello aquel ánimo cuyas virtudes están en armonía" ${ }^{36}$.

La belleza se define como una gracia que se vincula a un agrado de las cosas armónicas. La gracia es el encanto. Las cosas pueden ser bellas por sus perfectas proporciones, o bien por la

\footnotetext{
${ }^{34}$ Francesco Petrarca, "La belleza corporal (Diálogo entre Júbilo y la Razón)”. En Tatarkiewicz, Wladyslaw, Op.cit., p.22. "GAUDIUM: Forma corporis eximia est... egregia est... elegantisima est..., mira est..., magna est..., rara est..., clara est..., excellens est... RATIO: Quam mallem formam animi excellentem! Est enim et sua animae pulcritudo, multo suavior certiorque quam corpori, et ipsa quoque suis legibus decore ordinis atque apta suarum partium dispositione subsistens [...] GAUDIUM: Ut virtus animi corporis forme iuncta sit, studeo» [Francesco Petrarca, De remediis utriusque fortune, I, 2: De forma corporis, ed. 1628, pp.47 y ss. Disponible en: https://archive.org/details/bub_gb_FG4-cCgjuxsC] (Noviembre, 2017).

${ }^{35}$ Tatarkiewicz, Wladyslaw. 1991. Historia de la Estética, p.16.

${ }^{36}$ Pietro Bembo, "La belleza radica en la armonía”, Gli Ansolani, p.129. En Tatarkiewicz, Wladyslaw, Op.cit., pp.154155. «Percio che ella non è altro, che una gratia, che di proportione e di convenienza nasce, e d'harmonia nelle cose, la quale quanto è più perfetta ne'suoi suggetti, tanto più amabili essere se gli fa e più vaghi, et è accidente negli huomini non mèno dell'animo che del corpo. Percio che si come è bello que corpo le cui membra tengono proporzione tra loro, cosi è bello que'llanimo, le cui virtù fanno tra sé harmonia» [Pietro Bembo, Gli Asolani, [14971502] ed. 1525, p.187. Disponible en: https://archive.org/details/ bub_gb_ePJV8aiwdJOC] (Noviembre, 2017).
} 
gracia $^{37}$. Tal como se aprecia en la mirada de Bembo, la gracia refleja un gusto y complacencia en la belleza de las cosas, basada en la proporción, la conveniencia y la armonía, lo que devela la perfección del objeto.

Si revisamos la percepción de belleza de Leon Battista Alberti en su Tratado de Arquitectura, redactado entre 1449-1450, apreciaremos:

“Mas qué es la Belleza y qué el ornato en sí, y qué diferencia hay entre ellos, quizás lo entenderemos mejor mediante el ánimo, pues no me es fácil explicarlo con palabras. Pero para ser breves, la definiremos de este modo, diciendo que la belleza es un concierto de todas las partes acomodadas entre sí, con proporción y discurso, en la cosa en que se encuentran, de manera que no se le pueda añadir o disminuir o cambiar nada sin que esté peor. Cosa es ésta por cierto tan grande y divina y en darle perfección consumen sus fuerzas las artes y el ingenio, pues raramente se le concede a alguno, ni siquiera a la Natura, que nos presente nada que esté del todo acabado y ya perfecto en todos sus aspectos" ${ }^{38}$.

Asimismo, en otro fragmento se señala acerca de la belleza:

"Pues belleza es cierto consenso y concordancia de las partes, en la cual se pretende que dichas partes se encuentren, cuya concordancia se habrá obtenido en efecto con cierto determinado número, acabamiento y colocación, tal como la armonía, es decir, el principal intento de la naturaleza lo buscaba" ${ }^{39}$.

La noción de belleza de Alberti considera la proporción de las partes, las cuales en su plena concordancia establecen una perfecta armonía de las cosas. Según Raymond Beyer, la definición de belleza de Alberti se basa en la concinnitas, es decir, "una cierta conveniencia razonada en todas las partes. Es la armonía, la perfección" ${ }^{40}$. En este sentido, la belleza se

\footnotetext{
${ }^{37}$ Tatarkiewicz, Wladyslaw. 1991. Historia de la Estética, p.247.

38 Leon Battista Alberti, "Definición de lo bello", De re aedificatoria, VI. En Tatarkiewicz, Wladyslaw, Op.cit., p.116. «Ma che cosa sia Bellezza \& ornameto da per se, \& che differetia sia infra di loro, forse lo intenderemo piu apertamente con lo animo, che à me no fara facile di esplicarlo con le parole. Ma noi per effer breui la diffiniremo in questo modo, \& diremo, che la Bellezza è un concertó di tutte le parti accomodate insieme con proportione, e discorso, in quella cosa, in che le si retrnovano; di maniera che e' non vi si possa aggingnere, o diminuire, o mutare cosa alcuna, che non vi stesse peggio. Et è questa certo cosa grande, e divina. Nell' dar perfettione, allaquale si consumano tutte le forze delle arti, e de lo ingegno, e di raro è consesso ad alcuno, nè ad essa Natura ancora, che ella metta inanzi cosa alcuna che sia finita del tutto, e per ogni conto perfetta» [Leon Battista Alberti, Della Architettura, ed. 1565, Libro VI, Cap. 2, 10-16, p.120. Disponible en: http://digibug.ugr.es/handle/10481/11627\#.Vj6AxrcvfIU] (Noviembre, 2017).

39 Leon Battista Alberti, "Definición de lo bello", De re aedificatoria, IX, 5. En Tatarkiewicz, Wladyslaw, Op.cit., p.117. "Che la Bellezza, è un certo concenso, e concordantia delle parti, in qual si voglia cosa che dette parti si ritrouvino, la qual'concordanzia si sia havuta mente con certo determinato numero, finimento e collocatione, qualmente la leggiadra cioè, il principale intento della natura, ne ricercava» [Leon Battista Alberti, Della Architettura, ed. 1565, Libro IX, Cap. 2, 24-27, p.257. Disponible en: http://digibug.ugr.es/handle/10481/11627\#.Vj6AxrcvfIU] (Noviembre, 2017).

${ }^{40}$ Bayer, Raymond. 2002. Historia de la estética, p.105.
} 
encuentra en la naturaleza, en las creaciones humanas y en el arte, reflejando una proporción de todas las partes: un cuerpo armónico y bien dispuesto. Esta armonía expresa un orden tanto en la forma y proporción de las partes, al igual que del contenido, entorno y disposición del objeto $^{41}$.

Junto con esto, Leonardo da Vinci en su Tratado de la Pintura, colección de escritos del artista publicado póstumamente en 1651, establece una diferencia entre la belleza y la fealdad:

"Y cuanto más cuidado se ponga en colocar en un cuadro al lado de un hermoso un feo, al de un viejo un joven, y al de un fuerte y valeroso un débil y pusilánime, tanto más agradable será, y tanta mayor belleza tendrán respectivamente las figuras" ${ }^{42}$.

Mediante este pasaje podemos apreciar cómo lo bello se opone a la fealdad, brutto, en cuanto la belleza refleja lo agradable para las personas. Según Luis Farré, Leonardo da Vinci aplica un método analógico, en el cual contrapone conceptos en forma absoluta, es decir, el bien supera al mal, la verdad al error y lo bello a lo feo ${ }^{43}$. En cierta medida, podemos notar cómo lo bello constituye una belleza absoluta, de un valor superior a lo feo. En este caso concreto, contrapone una hermosura basada en la 'fortaleza' y 'juventud' frente a una fealdad compuesta de la 'vejez' y 'debilidad'44.

En torno a la estética de la fealdad, Leonardo Da Vinci también menciona la noción de lo ridículo:

"Si el pintor quiere ver bellezas que lo enamoren es muy dueño de engendrarlas, y si quiere ver cosas monstruosas y que espanten, o que sean bufonescas y ridículas, o quizás que conmuevan, es Dios y señor de hacerlo" ${ }^{45}$.

\footnotetext{
${ }^{41}$ Tatarkiewicz, Wladyslaw. 1991. Historia de la Estética, p.113. Hay que tener presente que la proporción que aprecia Alberti considera un cierto juicio que la naturaleza ha puesto en el alma del hombre, esto es, el juicio del ojo. En otras palabras, mediante este juicio sensible de la vista se puede alcanzar una apreciación de la hermosura y proporcionalidad de las cosas, las cuales deben agradar al ojo, la sensibilidad, como resultado de la belleza [Summers, David. 1993. El juicio de la sensibilidad, pp.188-191].

${ }^{42}$ Leonardo da Vinci, Tratado de la Pintura, Imprenta Real, Madrid, 1827, XCVIII, p.46. "E quanto osseruerai più in una historia, ch'il il brutto sia vicino al bello, \& il vecchio al giouane, \& il debole al forte, tanto più vaga farà la tua historia, el'una perl'altra figura accrescerà in belleza» [Lionardo da Vinci, Trattato della Pittura, ed. 1651, Cap. LXXXXVIII, pp.25-26. Disponible en: https://archive.org/details/gri_33125008484301] (Noviembre, 2017).

${ }^{43}$ Farré, Luis. 1950. Estética, Buenos Aires, Editorial Difusión, p.165.

${ }^{44}$ Hay que tener presente que la noción de fealdad se concibe como lo desagradable, aquello que carece de belleza, lo deforme y vergonzoso [Souriau, Étienne. 2010. Diccionario Akal de Estética, Madrid, Akal, p.577]. A fines de la Edad Media y el Renacimiento, lo feo tiene una imagen negativa, de privación, es lo no bello, y que es contrario al esplendor y claridad. Este concepto se identifica con aquello que viene «de fuera, de abajo o lo tenebroso» [Rodríguez Tous, Juan Antonio. 2002. Idea estética y negatividad sensible. La fealdad en la teoría estética de Kant a Rosenkranz, Barcelona, Suplementos Er, pp.59-60].

45 Leonardo da Vinci, Trattato della Pittura, Codex Vaticanus, Urbinas, ed. H. Ludwing, 1882, Cap. XIII. En Tatarkiewicz, Wladyslaw, Op.cit., p.170. "Se'l pittore vol vedere bellezze, che lo innamorino, egli n'è signore di generarle, et se vol vedere cose monstruose che spaventino, o che sieno bufonesche e risibili, o veramente compassionevoli, ei n'è signore e Dio» [lbíd.].
} 
Incluso, Leon Battista Alberti menciona este concepto de lo ridículo:

"Igualmente la figura que tenga la cara llena y abultada, será muy impropio que tenga los brazos delgados y consumidos; y al contrario, el que pintase a Aqueménides con aquel semblante con que dice Virgilio que le halló Eneas en la Isla, debe ponerle los demás miembros con la misma extenuación y debilidad, pues de otro modo sería muy ridículo" ${ }^{46}$.

El concepto de risibili o molto ridicolo constituye lo 'ridículo', aquello relacionado al escarnio y la burla, es lo bufonesco. Es una noción que se asocia a lo desproporcionado y lo torpe, que no sigue los lineamientos de la mesura y la belleza, conformando parte de la fealdad ${ }^{47}$. Tal como expresa Étienne Souriau, lo ridículo se define como lo divertido y lo chistoso, una categoría estética que incluye lo pintoresco. Es la extravagancia por lo grotesco ${ }^{48}$. Asimismo, Karl Rosenkranz indica que lo ridículo desfigura la imagen positiva de lo bello, donde se torna lo informal, lo incorrecto, lo vulgar y lo repugnante ${ }^{49}$. Incluso, como señala Mijael Bajtin, lo ridículo es lo no serio, la bufonería, lo que causa risa, representando lo bajo e inferior ${ }^{50}$. A partir de los pasajes notamos cómo la belleza se basa en la proporción de los cuerpos en la pintura, es decir, si tiene un cuerpo gordo, se vería muy ridículo con brazos delgados. En este sentido, la noción de lo ridículo se vincula a aquello extraño o extravagante que va en contra de una determinada realidad de una cosa; más concretamente, lo ridículo puede causar risa o burla por la fealdad, desproporción y torpeza de algún sujeto/objeto.

En suma, mediante estos diversos pasajes es posible apreciar de qué manera los intelectuales y artistas renacentistas construyen una visión estética centrada en las ideas de belleza y fealdad. En cierta medida, destacan las nociones de disposizione di corpo [disposición del cuerpo], bello [bello] y bellezza [belleza], las que se vinculan a un sentido de hermosura en los sujetos y cosas que se puedan observar. La belleza es lo que genera agrado tanto en su corporeidad, como también en su carácter interno del alma, la cual debe estar bien dispuesta y proporcionada en todas sus partes, generando una armonía perfecta en el ser. Por otra parte,

\footnotetext{
${ }^{46}$ Leon Battista Alberti, Tratado de Pintura, Imprenta Real, Madrid, 1827, Libro II, p.235. «E per il contrario dipingesse Achemenide ritrouatto da Enea nel'Isola col volto che Virgilio dice, ch'egli haueua, \& non ui seguissero l'altre cose conuenienti a la faccia, certo costui sarebbe un pittore molto ridicolo \& goffo» [Leon Battista Alberti, Della Pittura, ed. 1565, Libro II, 26-28, p.321. Disponible en: http://digibug.ugr.es/handle/10481/11627\#.Vj6AxrcvflU] (Noviembre, 2017).

${ }^{47}$ Cabe señalar que la idea de lo ridículo ya tiene sus raíces en la antigüedad, donde Aristóteles vincula a éste con la risa, lo gracioso (Poética 1449a, 31-36), o también Cicerón, quien considera que lo ridículo se relaciona con la fealdad moral o la deformidad física (De Oratore, II, 236). Una idea de lo ridículo que se conserva durante el Renacimiento, emparentándose con lo deforme y lo feo [Coca R., Fatima. 2005. "La influencia social en la concepción de lo ridículocómico a través de la comedia", Tonos, Revista Electrónica de Estudios Filológicos, núm. 10, Universidad de Murcia. En: https://www.um.es/tonosdigital/znum10/estudios/G-Coca.htm (Noviembre, 2017).

${ }^{48}$ Souriau, Étienne. 2010. Diccionario Akal de Estética, p.952.

${ }^{49}$ Rosenkranz, Karl. 1992. Estética de lo feo, Colección Imaginarium, n.5, Madrid, Julio Ollero Editor, p.176.

${ }^{50}$ Bajtin, Mijael. 2003. La cultura popular en la Edad Media y el Renacimiento, Madrid, Alianza, pp.72-73.
} 
también se encuentran nociones de lo brutto [feo], risibili [risible] y molto ridicolo [muy ridículo], las que reflejan el desagrado por la fealdad y ridiculez de algo, aquello que suscita risa por su rareza, extravagancia, desproporción o torpeza, generando una imagen contraria al ideal de armonía y belleza de la época.

\section{La visión estética en los viajes de Antonio Pigafetta}

El cronista Antonio Pigafetta a lo largo de sus viajes menciona el encuentro con una otredad para él exótica, distinta y asombrosa. En este encuentro se refiere a la percepción del otro, dando cuenta de las características de los pueblos, sus formas de vida y costumbres, como también la flora y fauna de los lugares que recorre. A partir de su relato, podemos apreciar cómo Pigafetta sí utiliza una visión estética en la otredad, aplicando un lenguaje de la belleza y fealdad, el cual conforma parte de la tradición humanística e intelectual del mundo renacentista.

Pigafetta ya en su recorrido por las tierras asiáticas, específicamente la isla de los Ladrones, señala:

"Cada uno de estos indígenas vive como quiere; no tienen jefe, van desnudos, algunos con barba y los cabellos muy negros les llegan hasta la cintura; llevan sombreros de palma como los albaneses, son tan altos como nosotros y bien proporcionados. No adoran nada; su piel es aceitunada, aunque cuando nacen son blancos; llevan los dientes pintados de rojo y de negro porque lo encuentran bellísimo. Las mujeres van desnudas cubriéndose solo sus partes naturales con una tira de una membrana, sutil como el papel, que se encuentra entre la corteza y el tallo de la palma. Estas mujeres son bellas, delicadas y más blancas que los hombres; llevan los cabellos sueltos, negrísimos, que les llegan casi hasta el suelo" ${ }^{\prime 51}$.

Mediante este pasaje podemos observar de qué manera los indígenas van 'desnudos' [ignudi], son 'grandes' [grandi] y 'bien formados' [ben formati]. En cierta medida, el viajero presta atención a las características físicas de las gentes de la isla de los Ladrones, donde juzga positivamente a los nativos. En el caso de las mujeres, éstas son bellas, delicadas y más blancas que los hombres ${ }^{52}$. La noción de belle se vincula a una hermosura corporal, bien proporcionada y delicada de las personas. Si tomamos en cuenta las otras ediciones del viajero italiano, ya en

\footnotetext{
${ }^{51}$ Antonio Pigafetta, El primer viaje alrededor del mundo, ed. Isabel de Riquer, Op.cit., p.117. «In questa gente, per quanto potemmo osservare, ognuno vive come più gli aggrada, non avendo altra legge che la propia volontà. Essi non adoran nulla; nè v'è fra loro alcuno che commandi agli altri. Vanno assato ignudi. Alcuni di loro sono barbuti, con capegli Neri che cadono sino alle reni; ma alcuni gli annodan ful capo. Porta in testa de'piccoli cappelli di palma, di forma simile a quelli degli Albanesi. Sono grandi quanto noi e ben formati. Sono olivastri, ma nascono Bianchi: i denti loro son rossi e Neri artificialmente, perché reputan ciò elsere una bellissima cosa. Le donne son belle, di figura svelta, più dilicate e bianche degli uomini, con capegli nerissimi sciolti e lunghi sino a terra» [Antonio Pigafetta, Primo viaggo intorno al globo, ed. Carlos Amoretti [1524-1525], pp.51-52].

${ }^{52}$ Cfr. Safford, W. E. 1902. "Guam and its people", American Anthropologist, vol. 4, núm. 4, p.715.
} 
la versión de 1536 menciona: "sono di statura grandi come noi \& ben disposti, di colore l'uliuo, anchor che naschino bianchi" ${ }^{53}$, e incluso en la versión francesa del librero Simone Colines de París de 1526-1536, indica: "Ils sont grands come nous / bien disposes" ${ }^{54}$. A través de estos pasajes es posible apreciar la noción de ben disposti o bien disposes, que alude a la 'buena disposición', el estar 'bien formado', es decir, contar con buenas proporciones corporales que otorgan belleza y armonía en sí. Esto sigue los lineamientos de percepción de belleza de los humanistas e intelectuales de su época, en cuanto la belleza es un orden y disposición, que busca una exactitud en la representación de las formas y las figuras ${ }^{55}$.

En el caso de la Patagonia, menciona a un gigante bien proporcionado:

“Un día, cuando menos lo esperábamos, un hombre de aspecto gigantesco se presentó ante nosotros. Estaba sobre la arena casi desnudo, cantaba y danzaba al mismo tiempo, echándose polvo sobre la cabeza [...] Era tan grande, aunque bien proporcionado, que nuestras cabezas llegaban apenas a su cintura" ${ }^{56}$.

Incluso, en otra escena, habla de un hombre mejor formado:

“Este hombre era más grande y estaba mejor formado que los otros y era más tratable y amistoso; cuando bailaba, daba unos saltos tan altos que sus pies se elevaban un palmo de la tierra" ${ }^{57}$.

Hay un interés por representar las buenas proporciones físicas de los nativos, resaltando su desnudez, cuerpos grandes y bien formados. El otro es representado bajo los ojos del europeo. En cierta medida, resulta importante para los viajeros que recorren las nuevas tierras generar una impresión atractiva de las gentes y lugares que exploran; son gigantes, otros, ${ }^{58}$ pero al

\footnotetext{
53 Antonio Pigafetta, Il viaggo fatto da gli Spagniuoli a torno a'I mondo, 1536, p.47.

${ }^{54}$ Antonio Pigafetta, Le voyage et navigation faict par les Espaignolzes isles de Mollucques, 1526-1536, cap.XXV

${ }^{55}$ Hay que tener presente que en el contexto de su época si algo agrada, es porque tiene orden y proporción. Ya Leon Battista Alberti manifiesta que la belleza refleja "la armonía y buena proporción, la consonancia e integración mutua de las partes", o tal como indica L. Ghiberti, la proporcionalidad solo crea belleza. Incluso, Alberto Durero señala que "sin una proporción adecuada, ninguna figura puede ser perfecta" [Tatarkiewicz, Wladyslaw. 2001. Historia de seis ideas. Arte, belleza, forma, creatividad, mímesis, experiencia estética, Madrid, Tecnos, pp.159-160].

${ }^{56}$ Antonio Pigafetta, El primer viaje alrededor del mundo, ed. Isabel de Riquer, Op.cit., pp.90-91. «Un giorno ci comparve all' improvviso un'uomo di statura gigantesca che stava quasi ignudo full'arena del porto ballando e cantando, e gettadosi della polvere sul capo [...] Si grande era quest'uomo che noi gli davamo alla cintura, ed era assai ben fatto di corpo" [Antonio Pigafetta, Primo viaggo intorno al globo, ed. Carlos Amoretti [1524-1525], pp.2425].

57 Antonio Pigafetta, El primer viaje alrededor del mundo, ed. Isabel de Riquer, Op.cit., pp.92-93. «Costui era più grande e meglio fatto degli altri, e più trattabile e grazioso: ei ballava, e faltava con tanto vigore che nel ricadere immergeva quasi per un palmo i piedi nell'arena» [Antonio Pigafetta, Primo viaggo intorno al globo, ed. Carlos Amoretti [1524-1525], p.28].

${ }^{58}$ Sobre la representación del patagón como gigante, véase: Flores de la Flor, M. Alejandra. 2014. "Los relatos de viajes al Océano Pacífico: el Estrecho de Magallanes y la leyenda de los Patagones", Tiempos Modernos, vol. 8, núm. 28, pp.1-28; y Castro H., Pablo. 2012. "Monstruos, rarezas y maravillas en el Nuevo Mundo. Una lectura a la visión
} 
mismo tiempo cuentan con cuerpos 'bien y mejor hechos' [ben fatto e meglio fatto], lo que constituye un ideal para la sociedad renacentista ${ }^{59}$. Junto con esto, el gigante es 'trattabile e grazioso', lo que nos permite aproximar la idea de belleza a la gracia. Tal como expresa Michael Baxandall, la grazia oscila entre un carácter objetivo y subjetivo, esto es, poseer gracia y agradar en general ${ }^{60}$. En este sentido, es una belleza que expresa no solo una hermosura corporal y proporcionada en sí, sino que además manifiesta un carácter espiritual, carismático, que tal como ocurre con este nativo que danza y da grandes saltos, resulta ser grazioso, como un complemento elemental de su belleza bien dispuesta.

También se refiere a cuatro mujeres bellas, blancas y desnudas en Oriente:

"Eran unas jóvenes muy bellas, de piel clara y de figura proporcionada como nuestras mujeres. Vestían tan solo con una tela de corteza de árbol que les cubría desde la cintura hasta las rodillas; otras iban completamente desnudas" ${ }^{\prime 1}$.

Y el caso de la reina joven y bella:

"La reina era joven y bella, vestía una túnica blanca y negra que la cubría toda; los labios y las uñas estaban pintados de color rojo muy vivo, sobre la cabeza un gran sombrero de hojas de palmera que le servía de quitasol y que estaba rodeado de una corona de las mismas hojas" $^{62}$.

europea de los indios de la Patagonia y Tierra del Fuego mediante la cartografía de los siglos XVI y XVII", Revista Sans Soleil, núm. 4, pp.30-52.

${ }^{59}$ Ya en la edición de 1536, e incluso en la de 1550 de Ramusio, la noción de ben disposto predomina en los pasajes: "Gigante maggiore \& meglio disposto chegli altri" [Gian Battista Ramusio, Navigazioni e viaggi, 1550, p.381v] o "Era molto ben disposto" [Antonio Pigafetta, Il viaggo fatto da gli Spagniuoli a torno a'l mondo, 1536, p.40], dando cuenta cómo Pigafetta aplica en su visión estética la noción de 'buena y mejor disposición'. Tal como indica Michael Baxandall, si tomamos en cuenta la educación de los humanistas del Quattrocento, estos poseen "una disposición hacia la experiencia visual, dentro o fuera de los cuadros, que adquiría maneras especiales: prestar atención a la estructura de formas complejas, como combinaciones de cuerpos geométricos regulares y como intervalos comprensibles en serie. Como tenían práctica en manejar proporciones y en analizar el volumen y la superficie de los cuerpos, eran sensibles a los cuadros que tuvieran procesos similares" [Baxandall, Michael. 1978. Pintura y vida cotidiana en el Renacimiento. Arte y experiencia en el Quatroccento, Barcelona, Gustavo Gili, p.129]. En otras palabras, el viajero como humanista también se circunscribe en un ambiente de relación estética y experiencia visual, en el cual manifiesta sus apreciaciones sobre la proporcionalidad y belleza de los cuerpos.

${ }^{60}$ Ibíd., p.160.

${ }^{61}$ Antonio Pigafetta, El primer viaje alrededor del mundo, ed. Isabel de Riquer, Op.cit., pp.142-143. «Quelle fanciulle erano assai belle, e bianche poco meno delle nostre donne; e sebben fossero gia adulte pur erano ignude» [Antonio Pigafetta, Primo viaggo intorno al globo, ed. Carlos Amoretti [1524-1525], p.82].

${ }^{62}$ Antonio Pigafetta, El primer viaje alrededor del mundo, ed. Isabel de Riquer, Op.cit., p.149. «La Regina era giovane ancora e bella, colla bocca e le ugne rossissime. Era tutta coperta d'un panno bianco e nero, con un gran cappello in capo formato di foglie di palma a soggia di parasole, ed una corona simile al triregno papale, formata cole foglie medesime. Non va mai in alcun luogo senza questa corona» [Antonio Pigafetta, Primo viaggo intorno al globo, ed. Carlos Amoretti [1524-1525], pp.88-89]. 
En estos pasajes notamos cómo el navegante destaca las bellezas de las mujeres que observa, tanto en las 'jóvenes muy bellas' y 'la reina que es joven y bella' ${ }^{63}$. La belleza para Pigafetta se relaciona a la juventud, puesto que significa frescura, lozanía y jovialidad. Incluso, en otro pasaje de la versión Ambrosiana encontramos cómo el viajero italiano se refiere a la belleza relacionada a la juventud en una mujer de Brasil: "Una bella giovane venne sulla nave" ${ }^{\prime 64}$. Tal como expresa Alicia Martínez Crespo, la juventud se asocia al sentido de belleza y atractivo femenino, en tanto que la vejez desfigura ese ideal de hermosura ${ }^{65}$. La juventud constituye el regocijo, la plenitud, una belleza fresca, frente a la vejez que se concibe como una etapa de decrepitud. Asimismo, también notamos cómo se exalta la noción de la tez blanca, "Quelle fanciulle erano assai belle, e bianche poco meno delle nostre donne" ${ }^{66}$, o en otro pasaje: "Le donne son belle, di figura svelta, più dilicate e bianche degli uomini" ${ }^{67}$. Jacob Burckhardt señala que el ideal de belleza renacentista considera la piel blanca como parte de la belleza femenina, la cual debe manifestarse en un blanco vívido en todas las partes de su cuerpo $^{68}$, delineando frescura y pulcritud ${ }^{69}$.

Por otro lado, podemos vislumbrar cómo Pigafetta se refiere a nociones de fealdad en sus viajes:

"Los habitantes de estas islas son salvajes y viven como animales; comen carne humana, no tienen rey y van desnudos, excepto aquella corteza de la que ya he hablado muchas veces. Pero cuando van a combatir se cubren el pecho, la espalda y los costados con pieles de búfalo, adornados de conchas, colmillos de cerdo y rabos de cabra atados por delante y por detrás. Llevan los cabellos recogidos en lo alto de la cabeza, bien sujetos con peinetas de caña que pasan de lado a lado. Se enrollan la barba con hojas y meten las tiras dentro de

\footnotetext{
${ }^{63}$ Cabe destacar que en la edición de 1536 se expresa: "quattro figliude molto belle \& bianche, como sone le nostre, qual sece, che ballarano in presentia delli nosti, estendo tutte nude" [Antonio Pigafetta, II viaggo fatto da gli Spagniuoli a torno a'l mondo, 1536, p.62]; en la versión de Simone Colines de París, "quatre filles moult belles et quafi blanches come les noftres" [Antonio Pigafetta, Le voyage et navigation faict par les Espaignolzes isles de Mollucques, 1526-1536, cap. XXXI] y "La royne eftoit fort ieune \& belle" [Ibíd., cap. XLVI]. A partir de estos fragmentos, podemos notar cómo se resalta la belleza de las cuatro jóvenes, que son bellas y blancas, como también la reina que es muy joven y bella.

${ }_{64}$ Antonio Pigafetta, Primo viaggo intorno al globo, ed. Carlos Amoretti [1524-1525], p.22.

${ }^{65}$ Martínez C., Alicia. 1993. "La belleza y el uso de afeites en la mujer del siglo XV", DICENDA, Cuadernos de Filología Hispánica, núm.1, Madrid, 1993, p.204.

${ }^{66}$ Antonio Pigafetta, Primo viaggo intorno al globo, ed. Carlos Amoretti [1524-1525], p.82.

${ }^{67}$ Ibíd., p.52.

${ }^{68}$ Burckhardt, Jacob. 1952. La cultura del Renacimiento en Italia, pp.268 y ss.

${ }^{69}$ Cabe señalar que el color blanco es "un eje de evaluación en su prejuicio contra el negro". El color negro "pasa a ser un aspecto estético de 'fealdad", reflejando lo 'inferior' y lo 'malo'. De hecho, "se infiere como un opuesto al resaltar la belleza, al comparar dos personas o cosas, o sencillamente se declara un aspecto selecto como 'feo' para indicar que el otro no lo es". El color claro refleja belleza para la estética europea, mientras que el otro de color posee inferioridad estética e intelectual, en la cual se expresa una dicotomía de la tradición judeo-cristiana en la que el mal se asocia con lo negro y lo bueno con lo blanco [Sánchez, Josué. 2001. "La primera visión europea estética de los indoamericanos en la invasión a América", p.84].
} 
pequeñas cañas; es algo verdaderamente ridículo y es el pueblo más feo que hay en todas las Indias"70.

Incluso, en otro pasaje sobre la fealdad de las mujeres de Indonesia: "Las mujeres son feas y van desnudas como las otras" ${ }^{71}$.

Podemos apreciar cómo el viajero italiano menciona la noción de fealdad en la otredad. Se refiere a estos pueblos como brutti uomini, esto es, hombres feos, e incluso en Indonesia señala que las mujeres son brutte, es decir, feas ${ }^{72}$. Es una fealdad asociada a la ridiculez del aspecto físico de los nativos, ya sea por los cabellos recogidos en lo alto de la cabeza con peinetas de caña, como también por enrollarse la barba con hojas, metiendo las tiras en pequeñas cañas. Esto resulta molto ridicolo, motivo de burla por el desagrado estético que para él significa. En la versión italiana de 1536, se escribe: "similmente che fa rider chi gli vede" ${ }^{\text {"73 }}$, es decir, se ríen solo de verlos. La percepción de fealdad considera esta relación con la burla, la risa, lo grotesco, aquello que es bajo e inferior, y que se aleja de la belleza ideal imperante en el mundo del que procede.

Finalmente, observamos cómo menciona lo ridículo en las tierras de Brasil:

"Estas gentes [los brasileños] llevan tatuado todo el cuerpo y el rostro de diversas maneras, y también las mujeres: es algo sorprendente. Van rapados y sin barba porque se la cortan; se visten con plumas de papagayo dispuestas de tal forma que las plumas más grandes se las ponen en círculo alrededor del trasero de manera algo ridícula" ${ }^{74}$.

\footnotetext{
${ }^{70}$ Antonio Pigafetta, El primer viaje alrededor del mundo, ed. Isabel de Riquer, Op.cit., p.236. «Gli abitatori di quest'isola sono selvaggi, e più bestie che uomini: mangiano carne umana: vanno ignndi se non che hanno la solita scorza d'albero intorno alle parti vergognose. Quando però vanno a combattere portano sul dorso, sul petto, e sui fianchi de' pezzi di pelle di bufalo, ornati di corniolli e di denti di porco, con code di pelle caprina attaccate dinanzi e di dietro. Portano i capegli sollevati in alto per mezzo di certi pettini di cana a lunghi denti sicchè passano da parte a parte. Involgono le loro barbe in foglie, e le chiudono in certe cannucce o tubi di cana cosa che parve a noi molto ridicola. Essi, in una parola, son a più brutti uomini che abbiamo veduti in queste Indie» [Antonio Pigafetta, Primo viaggo intorno al globo, ed. Carlos Amoretti [1524-1525], pp.167-168].

${ }^{71}$ Antonio Pigafetta, El primer viaje alrededor del mundo, ed. Isabel de Riquer, Op.cit., p.205. «Le femmine qui son brutte, e vanno ignude come le altre» [Antonio Pigafetta, Primo viaggo intorno al globo, ed. Carlos Amoretti [15241525], p.146].

${ }^{72}$ Según Umberto Eco, la fealdad es vista como lo contrario de lo bello, es la ausencia de forma, la asimetría, la falta de armonía, la desfiguración y la deformación. En suma, lo feo es simplemente lo opuesto de lo bello entendido como armonía, proporción e integridad [Umberto Eco. 2011. Historia de la fealdad, Barcelona, Lumen, p.16].

${ }^{73}$ Antonio Pigafetta, Il viaggo fatto da gli Spagniuoli a torno a'I mondo, 1536, p.99

${ }^{74}$ Antonio Pigafetta, El primer viaje alrededor del mundo, ed. Isabel de Riquer, Op.cit., pp.85-86. «I Brasiliesi sono olivastri anzi che Neri: vanno ignudi non coprendo nemmeno le parti sessuali; ma si dipingono stranamente tutto il corpo e'l volto col suoco in deverse maniere; e lo fanno le donne come gli uomini. Non hanno lunga capigliatura, ne' barba, ne' peli in alcuna parte, perche si pelano. Hanno vesti di piume di papagallo satte in maniera, che le grandi penne dell'uccello formano dietro un cerchio a ruota, che a nostri occhi era cosa assai ridicola» [Antonio Pigafetta, Primo viaggo intorno al globo, ed. Carlos Amoretti [1524-1525], p.19].
} 
El viajero italiano considera que la forma de vestir de los indígenas brasileños resulta ridícula en sí. Lo ridículo, lo risible, se funda en algo inocuo e inofensivo, pero que produce risa por su forma o actitud ${ }^{75}$. Ya esto se observa en la versión italiana de 1536 y la edición de Ramusio que transcribe el mismo pasaje: "Fanno le lor veste di penne di papagalli con una gran coda della parte di dietro, \& in tal maniera che ci face uan ridere vedendole" ${ }^{76}$. En cierta medida, podemos apreciar cómo le causa 'risa verlos', el modo en cómo se visten, cayendo en lo extravagante y lo ridículo.

En suma, mediante el relato de viajes de Antonio Pigafetta podemos apreciar de qué manera el viajero incluye en su narrativa una percepción estética de la otredad, refiriéndose tanto a elementos bellos, bien dispuestos y proporcionados, como aspectos que resultan ser feos, risibles y ridículos. El cronista italiano conserva en su lenguaje la visión estética de los humanistas e intelectuales renacentistas, creando un andamiaje de la alteridad que permite presentar su mirada personal y subjetiva de lo que observa, catalogando a los sujetos o grupos que vislumbra a partir de sus apreciaciones estético-culturales.

\section{Algunas consideraciones finales. La relación de Antonio Pigafetta y su visión estética de la otredad}

Si efectuamos un balance final acerca del estudio, podremos notar cómo a través de la relación de viaje de Antonio Pigafetta se establecen menciones de pueblos y elementos culturales que observa en su recorrido. Si bien realiza una anotación minuciosa de elementos materiales e inmateriales de las gentes, como también sus espacios, costumbres y formas de vida, no solo se dedica a describir, sino que también expresa su mirada sobre lo que aprecia. En este sentido, el viaje renacentista de Pigafetta se circunscribe en una noción de sensibilidad, siguiendo el planteamiento de David Summers, en la cual el viajero expresa su punto de vista y perspectiva individual sobre las cosas que observa ${ }^{77}$, pero al mismo tiempo, conserva los lineamientos socio-culturales de la visión estética de su época, aplicando dichas nociones para describir la realidad que observa.

La tradición de humanistas, intelectuales y artistas renacentistas forja una visión estética en la cual dejan fluir el juicio sensible, que permite consolidar la noción de individuo y subjetividad. En esta línea, se van a referir tanto a nociones de disposizione di corpo, bellezza y grazia, como

\footnotetext{
75 Cfr. Chico Rico, Francisco. 2009. "La risa en el contexto de la teoría literaria occidental”. En Ulpiano Lada (ed.), Literatura y humor. Estudios teóricos-críticos, Universidad de Oviedo, Oviedo, p.92.

${ }^{76}$ Antonio Pigafetta, Il viaggo fatto da gli Spagniuoli a torno a'l mondo, 1536, p.38; y Gian Battista Ramusio, Navigazioni e viaggi, 1550, p.380.

${ }^{77}$ Cabe destacar que el ojo se relaciona directamente con la mente, formando juicios y distinciones sobre las cosas particulares. En cierta medida, constituye un medio sensible para acceder a la belleza de las cosas y el mundo. A partir del sentido de la vista se establece una mirada individual y subjetiva de la realidad, dando cuenta del gusto, punto de vista y sensibilidad humana del sujeto [Cfr. David Summers. 1993. El juicio de la sensibilidad, p.247].
} 
también nociones de lo brutto, risibili y molto ridiculo, con lo cual manifiestan su percepción de belleza y fealdad sobre las cosas.

Ahora bien, no hay que perder de vista que la 'disposición del cuerpo', la 'belleza' y la 'gracia', constituyen elementos que definen lo agradable y lo hermoso, tanto en un carácter corpóreo y exterior, al igual que en un sentido interno y del alma, la que debe ser bien dispuesta, proporcionada y armónica, lo que permite generar un sentido de belleza ideal en el ser. Por otra parte, los aspectos de lo 'feo', 'risible' y 'muy ridículo', reflejan lo desagradable, extravagante y poco serio, provocando la risa por la fealdad y ridiculez de la forma, la cual no se ajusta al ideal de lo armónico y lo bello.

En el caso de Antonio Pigafetta, hemos demostrado que sí utiliza una visión estética acerca de la otredad, en la cual manifiesta su percepción de belleza y fealdad. De manera concreta, el viajero italiano menciona palabras como belle, ben formati, ben disposti, ben fatto, meglio fatto y grazia, con las cuales alude a un sentido de belleza, buena disposición, proporción y gracia en el otro, reflejando un sentido de lo agradable y lo hermoso que expresan una noción armónica. Incluso, menciona aspectos como brutto, molto ridicolo y ridere, que expresan tanto lo feo, lo ridículo y lo risible, en cuanto el viajero considera que hay pueblos desagradables y feos estéticamente, como también que causan risa por la rareza de sus costumbres, modos de vida o formas de vestir. En definitiva, mediante los viajes de Antonio Pigafetta es posible notar su percepción de la belleza y fealdad sobre el otro, dando cuenta de su juicio de la sensibilidad, en la cual a través de su ojo, su mirada y percepción subjetiva, construye una visión estética particular basada en las categorías de la tradición humanística e intelectual de su tiempo. Una mirada que se relaciona al punto de vista, la sensibilidad estética, que permite conocer una representación del otro y la realidad cultural del sujeto que construye su imagen.

\section{Bibliografía}

\section{Fuentes y Documentos:}

Antonio Pigafetta, El primer viaje alrededor del mundo. Relato de la expedición de Magallanes y Elcano, ed. Isabel de Riquer, Ediciones B, Barcelona, 1999

Antonio Pigafetta, Primo viaggo intorno al globo terracqueo, 1524-1525. En: http://bdhrd.bne.es/viewer.vm?id=0000060992\&page $=1$

Antonio Pigafetta, Le voyage et navigation faict par les Espaignolzes isles de Mollucques, 1526-1536. En: https://archive.org/details/levoyageetnauiga00piga

Antonio Pigafetta, II viaggo fatto da gli Spagniuoli a torno a'l mondo, 1536. En: http://www.europeana.eu/portal/record/2048604/data_item_onb_abo_2BZ156386803.html?start= $8 \&$ query $=$ who\%3Aantonio+pigafetta\&startPage $=1 \& q \mathrm{t}=$ false \&rows $=24$

Francesco Petrarca, De remediis utriusque fortune, I, 2: De forma corporis, ed. 1628. En: https://archive.org/details/bub_gb_FG4-cCgjuxsC

Gian Battista Ramusio, Navigazioni e viaggi, ed. 1550. En: http://www.europeana.eu/ portal/record/92004/BibliographicResource_2000059207873.html?start=19\&query=who\%3Aramusio \&startPage $=1 \& q f=$ TYPE\%3ATEXT\&qt=false\&rows $=24$ 
Giovanni Francesco Pico della Mirandola; Girolamo Benivieni, Dell'amore celeste e divino: Canzone, Lucca, 1731. En: http://reader.digitale-sammlungen.de/de/fs1/object/display/

bsb10754248_00132.html

Leon Battista Alberti, Della Architettura, ed. 1565. En: http://digibug.ugr.es/

handle/10481/11627\#.Vj6AxrcvfIU

Leon Battista Alberti, Tratado de Pintura, Imprenta Real, Madrid, 1827

Leonardo da Vinci, Tratado de la Pintura, Imprenta Real, Madrid, 1827

Lionardo da Vinci, Trattato della Pittura, ed. 1651. En: https://archive.org/details/gri_33125008484301

Pietro Bembo, Gli Asolani, [1497-1502] ed. 1525. En: https://archive.org/details/ bub_gb_ePJV8aiwdJ0C

\section{Obras generales y artículos de revistas:}

Adorno, Theodor. 1971. Teoría estética, Taurus, Madrid.

Bajtin, Mijael. 2003. La cultura popular en la Edad Media y el Renacimiento, Alianza, Madrid.

Bayer, Raymond. 2002. Historia de la estética, Fondo de Cultura Económica, México D.F., 2002.

Baxandall, Michael. 1978. Pintura y vida cotidiana en el Renacimiento. Arte y experiencia en el Quatroccento, Gustavo Gili, Barcelona.

Beuchot, Mauricio. 2012. Belleza y analogía. Una introducción a la estética, San Pablo, México D.F.

Burckhardt, Jacob. 1952. La cultura del Renacimiento en Italia, Losada, Buenos Aires, 1952.

Cachey Jr., Theodore. 2007. "Bio-bibliographical note". En Antonio Pigafetta, The first voyage around the world 1519-1522. An account of Magellan's expedition, University of Toronto Press, Toronto, Buffalo, Londres.

Castro H., Pablo. 2012. "Monstruos, rarezas y maravillas en el Nuevo Mundo. Una lectura a la visión europea de los indios de la Patagonia y Tierra del Fuego mediante la cartografía de los siglos XVI y XVII", Revista Sans Soleil, núm. 4, pp.30-52

Chastel, André. 1990. "El artista". En Eugenio Garin, El hombre del Renacimiento, Alianza, Madrid.

Chico R., Francisco. 2009. "La risa en el contexto de la teoría literaria occidental”. En Ulpiano Lada (ed.), Literatura y humor. Estudios teóricos-críticos, Universidad de Oviedo, Oviedo.

Coca R., Fatima. 2005. "La influencia social en la concepción de lo ridículo-cómico a través de la comedia", Tonos, Revista Electrónica de Estudios Filológicos, núm. 10, Universidad de Murcia. En: https://www.um.es/tonosdigital/znum10/estudios/G-Coca.htm

De Arriba, María Laura. 2004. "Los sonidos de la enunciación en la primera vuelta al mundo", Revista de Crítica Literaria Latinoamericana, Año XXX, núm. 60, Lima-Hanover.

De Riquer, Isabel. 1999. "Introducción”. En Antonio Pigafetta, El primer viaje alrededor del mundo. Relato de la expedición de Magallanes y Elcano, Ediciones B, Barcelona.

Eco, Umberto. 2010. Historia de la belleza, Lumen, Barcelona.

Eco, Umberto. 2011. Historia de la fealdad, Lumen, Barcelona.

Farré, Luis. 1950. Estética, Editorial Difusión, Buenos Aires.

Flores de la Flor, M. Alejandra. 2014. "Los relatos de viajes al Océano Pacífico: el Estrecho de Magallanes y la leyenda de los Patagones", Tiempos Modernos, vol. 8, núm. 28, pp.1-28

Givone, Sergio. 1999. Historia de la estética, Tecnos, Madrid.

Gombrich, Ernst. 2007. La historia del arte, Phaidon Press, Londres.

Hale, J. R. 1993. La Europa del Renacimiento, 1480-1520, Siglo XXI Editores, Madrid.

Hauser, Arnold. 1980. Historia social de la literatura y el arte, Guadarrama.

Luzzana C., Ilaria. 1992. Navegantes italianos, Mapfre, Madrid.

Martínez C., Alicia. 1993. "La belleza y el uso de afeites en la mujer del siglo XV", DICENDA, Cuadernos de Filología Hispánica, núm.1, Madrid. 
Massmann, Stefanie. 2014. "Geografías del imperio: utopía y desencanto en las representaciones del Estrecho de Magallanes (1520 y 1620)", Hispanófila, 172.

Pinkerton, John. 1819. "Pigafetta voyage round the world", A general collection of the best and most interesting voyages and travels in various parts of America, vol. I, Longman, Hurst, Rees and Orme and Brown, Londres.

Plazaola, Juan. 2007. Introducción a la estética. Historia, teoría, textos, Universidad de Deusto, Bilbao.

Robertson, James Alexander. 1906. "Bibliography of Pigafetta manuscripts and printed books". En Antonio Pigafetta, Magellan's voyage around the world, vol. 2, The Arthur H. Clark Company, Cleveland.

Rodríguez Tous, Juan Antonio. 2002. Idea estética y negatividad sensible. La fealdad en la teoría estética de Kant a Rosenkranz, Suplementos Er, Barcelona.

Rosenkranz, Karl. 1992. Estética de lo feo, Colección Imaginarium, n.5, Julio Ollero Editor, Madrid.

Ruiz M., Federico. 1922. "Prefacio del traductor francés". En Antonio Pigafetta, Primer viaje en torno del globo, Calpe, Madrid.

Safford, W. E. 1902. "Guam and its people", American Anthropologist, vol. 4, núm. 4, pp.707-729.

Sánchez, Josué. 2011. "La primera visión europea estética de los indoamericanos en la invasión de América", Anuario Americanista Europeo, núm. 9.

Sanfuentes, Olaya. 2009. Develando el Nuevo Mundo. Imágenes de un proceso, Ediciones UC, Santiago.

Schleiermacher, Friedrich. 2004. Estética, Verbum, Madrid.

Souriau, Étienne. 2010. Diccionario Akal de Estética, Akal, Madrid.

Summers, David. 1993. El juicio de la sensibilidad. Renacimiento, naturalismo y emergencia de la Estética, Tecnos, Madrid.

Tatarkiewicz, Wladyslaw. 1991. Historia de la Estética, La estética moderna, 1400-1700, III, Akal, Madrid.

Tatarkiewicz, Wladyslaw. 2001. Historia de seis ideas. Arte, belleza, forma, creatividad, mímesis, experiencia estética, Tecnos, Madrid.

Tenenti, Alberto. 2000. La Edad Moderna, siglos XVI-XVIII, Crítica, Barcelona.

Trías, Manuel. 1949. "El objeto de la estética", Actas del Primer Congreso Nacional de Filosofía, Mendoza. Walls y Merino, Manuel. 1899. "Prólogo del traductor". En Antonio Pigafetta, Primer viaje alrededor del mundo, Madrid.

Yarza, Joaquín. 2004. Introducción a la estética, EUNSA, Pamplona. 